In Focus

\title{
Production of Game Making Spaces: Disco Elysium and the game making community in Estonia
}

$\$$ sciendo 


\section{ABSTRACT}

This article discusses Disco Elysium in the context of the development of game making communities in Estonia and international production networks. Drawing on an analysis of secondary sources, in-depth interviews and a survey with game makers in Estonia, this article contributes to studies on national and regional gameproduction cultures. The aim of this article is two-fold. First, it contributes to studies of game production cultures by discussing the development and structure of gamemaking communities in Estonia. As such, it enriches the understanding of game production in Europe by providing empirical data about game making in Estonia. Second, based on the example of Disco Elysium, the article demonstrates how national, regional and international production networks contribute to the spatial politics of game production. In conclusion, this article emphasises the importance of the construction of space in game production and the asymmetries of power among game production regions.

The $15^{\text {th }}$ of October 2019, the release date of Disco Elysium, was an important date for the Estonian game maker community. The game developed by ZA/UM studio was published through a decade of creative and professional collaborations between Estonian game developers who later expanded their ambitious game to a multinational team of developers and support contractors. The game itself gained international acclaim and awards for its innovative game play, artistic visuals and portrayals of ideological tensions. The game also had economic and symbolic significance for the local game making community because it put Estonian game development on the map of international game production. Local media outlets proclaimed that the game's success was possible thanks to the Estonian game making community:

\begin{abstract}
thanks to game developing activists and events in Estonia there are more and more fruitful game development collaborations. One, if not the brightest diamond from Estonian game development is surely the role-playing video game called Disco Elysium. (Eesti Instituut 2020).
\end{abstract}

In this article, I will use the example of Disco Elysium to contextualise local, Estonian game production cultures. This investigation contributes to the theme of the special issue by providing readers with the game production context in which the game was developed and by drawing attention to positionality of local game makers to demonstrate how the struggle to establish a game making community in Estonia is interwind with regional infrastructure and 
international trends. This article draws from empirical research with game maker communities in Estonia (2019-2020) in order to account for the specific developmental trajectory of Disco Elysium and its significance to game makers in Estonia. The aim of this article is to draw attention to questions about socio-historical development of local and regional game making communities, asymmetries of power relations on the international game production networks, and the economic and socio-cultural meanings that are associated with the construction of game production spaces.

Unlike other forms of media and entertainment, digital games are rarely developed for national markets. However, national, and regional socio-historical development and positionality of game making communities has an impact on how spaces of games production are constructed and defined in the context of international game production. Who makes games in a given national context, and where and how they are made is influence by many socio-historical factors, such as, positionality to other media industries in the countries, access to reliable infrastructure, economic barriers, and political power. This contextualisation of local game making cultures could be only partially understood without questions of complex international production networks in game development whereas different levels of spatial analysis: local, national, regional, and international levels intersect and highlighting asymmetrical power relations (Kerr 2014). Critical political economy traditions utilise the concept of spatialisation in analysis of media industries to emphasise the meaning of place, space and power in media productions that span local, regional, and international boundaries (Mosco 1996: 157). The concept of spatialisation refers to "the process of overcoming the constraints of space and time in social life" (ibid.). In other words, this type of analysis demonstrates how spatial relations of various institutions, companies, commodities, and people are transformed and redefined in the capitalist mode of production, through the power of transportation and communication (ibid.). Spatialization attends to how the capitalist mode of production transforms spatial relations of various institutions, companies, and commodities. This concept is also used in the study of game production to indicate international production networks in the game industry and the shaping of certain places and regions due to the sociohistorical development of game cultures as well as the industry's ability to influence transnational media companies in different spaces and locations (Kerr 2014: 28).

In this article, I turn to the concept of spatialisation and construction of game production spaces to position the development of Disco Elysium within the socio-historical emergence and growth of game making communities in Estonia. The rationale for this investigation is two-fold. First, this article contributes to the body of research about national and regional game production by investigating game making communities in Estonia. Europe is often presented as one of the important game software production regions, however, this statement undermines the complexities and differences among different national and local game production cultures (Kerr 2014). European game industries are often addressed through discourses of "potential," often for national economic development (Nieborg, de Kloet 2016). However, these discourses obscure differences in socio-historical development, access to infrastructure, political and economic situations of given nations and regions in terms of ICT and game industry development. Therefore, this contribution enriches our understanding of game production communities in European contexts, through investigating the game development community in Estonia. Second, in this contribution, I argue that multi-spatial analysis in understanding the construction of game production spaces provides important insights into the dynamics of local game making communities and their relationship to the global game industry.

This article is structured as follows. The first section presents a brief overview 
of studies about spatialisation and the cultural context of game production. This section is followed by a discussion of research methods. The findings and discussion section are divided into three sub-sections. First, I will focus on the socio-historical development of the Estonian game making community and their position within the Baltic Sea region. The second section addresses the significance of Disco Elysium for the development of the game making community in Estonia in its social, economic, and cultural sense. The third section draws attention to international production networks to understand how and where Disco Elysium was developed.

\section{SPATIAL POSITIONING OF GAME PRODUCTION CULTURES}

For media studies, the investigation of complex production networks in various media industries demonstrates how media production operates across local, regional and international boundaries (e.g. Christopherson 2006). The acknowledgment of the extensiveness and complexity of production networks has also a part of studies of game production (Kerr 2017). These studies establish that software and hardware production in the industry is highly regionalised (Johns 2006), with software development in the 1980s dominated by companies from North America and Japan, and since 2010 with the growing importance of Chinese and South Korean companies (Kerr 2017). Furthermore, the leading game software production regions are also dependent on a network of game studios, service and localisation companies which indirectly and directly support international game development.

To position a given game production culture is to understand it within its sociohistorical context and associated local infrastructure, as Kerr argues:

the spatial distribution of the games industry is complex and linked in part to the history of the games industry but more significantly to the regional structure of software production networks interacting with local and regional financial, cultural, and labour markets. (2014: 28-29)

Drawing on studies about game production cultures in Finland, Sotamaa (2021) indicates that being attentive to local and regional production cultures leads to uncovering specific practices, meanings, identities, and organisations specific to game production. Indeed, studies which engaged in investigating national and local game production cultures demonstrated that pre-existing infrastructure, connections to other digital media or media industries, and the cultural legitimacy of regional games cultures are important in understanding the development of game industries, their structure and organisational practices. For example, Izushi and Aoyama (2006) discussed how the well-established animation industry in Japan supported development of digital games industries. Jørgensen et al. (2017) discussed the development of the "demo scene" in Nordic countries and its contribution to the development of the digital games industries in Norway, Sweden, and Finland. Scholars also investigated national and regional games industries as they relate to the international game development networks. Kerr and Cawley (2012) discussed Ireland as an important place for game production in terms of middleware development and community services for the global game industry.

Studies that aim to contextualise game making practices in a given geographical or state location utilise different levels of analysis and theoretical traditions; from focusing on boundaries defined by national states, the position of workers through the sociology of work (e.g. Ozimek 2018), similarities and differences in regional developments (e.g. Liboriussen, Martin 2016) or taking the spatialisation approach to link different levels of analysis through which game production is shaped (Kerr, Crawley 2012). Tending to only one level of spatial analysis can be limiting 
in, for example, overstating national or regional boundaries in the flow of capital, commodities, and people in the game industry. While Sotamaa (2021) demonstrates attention to examining local and regional contexts and is often revealing of how international trends manifest in different locations, we need to be attentive when presenting how different spatial relations manifest in the context of a given national, local, or regional game production community.

To address this issue, scholars turn to the concept of spatialisation (Mosco 1996; Kerr 2017) which refers to "the process of overcoming the constraints of space and time in social life" (Mosco 1996: 157). This concept, widely used in the concept of the critical political economy, addresses how the capitalist mode of production transforms spatial relations of various institutions, companies, and commodities. However, Kerr (2014: 28) argues for broader investigation of spatial relations, following Henri Lefebvre's conceptualisation, to address not only actions and structures of given institutions but also various aspects of power in the construction of the meaning of spaces. This argument refers to Lefebvre's (1991/1974) engagement with other aspects of the social production of space, such as spatial practice, representation of space and spaces of representation. This conceptualisation provides a useful starting point in addressing the socio-historical construction of game production spaces beyond national and regional boundaries, by drawing attention to the constant spatial change and multi-spatial analysis required to understand game production.

This article contributes to these debates by focusing on the spatialisation of game production and its positionality within discussions about different levels of analysis in investigating local game making communities. I use Disco Elysium to demonstrate its meaning for the Estonian game community, and how its shapes thinking about the interplay of power in national, regional, and international spaces of game production. These questions are especially interested in game industries that are rarely operating or designated for national markets and operate as international commodities, competing in the international gaming market. These practices and networks span different geographical locations, while the political, economic, and social histories of a given region play a role in the formation of national games industries.

\section{RESEARCH METHODS}

The present work delineates findings from a larger research project which investigated working conditions in the Estonian digital games industry, focusing on the game making community (2019-2020). I present my findings based on the analysis of 23 semi-structured interviews with game makers, educators, and communication organisers from Estonia as well as survey data of the Estonian game industry $(n=$ 54) and fieldnotes from events organised for the local game-making communities in Tallinn and Tartu. I further contextualise these findings through the analysis of secondary materials, including reports about the game industries in Baltic countries (see Baltic Games Industry project), game development blogs and media outlet materials (e.g., published interviews with game developers).

These data sources illustrate the complex connections between local, regional, and international relations in the context of the Estonian game industry. Nevertheless, it is worth acknowledging barriers to data collection and analysis, such as the relatively small size of the local game-making community and its fragmentation. The interviewees in this study drew attention to the problem of assessing the size and structure of the local digital game industry, with ambiguity in the way companies associated with digital game development are defined and classified. For example, game industry data are included in a broader subcategory of creative industries defined as "entertainment software" (Estonian Institute of Economic Research [EKI] 2018:15-16). This category also includes information about the online gambling 
industry, including such companies as Playtech and Dervico, further inflating numbers about workers employed in this sector (EKI 2018: 15-16). However, the problem of assessing its size and composition refers to broader problems of accessing and evaluating data about local and regional game industries (Kerr 2006). The small size of the country is reflected in small number of companies involved in games development. According to data provided by the International Game Developers Association (IGDA) Estonia, there are approximately 80 companies related to games development in the country.

Data collected through interviews provided vital insights on the composition, dynamics, and historical development of local game-making communities. Interviewees were invited to take part in this study via a purposive, snowballing sampling strategy. The interview data sought to capture the perspectives of people who work or support the local game-making communities. The interviewees were given an information sheet about the research project and a signed consent form. The audiorecorded interviews lasted between 60-90 minutes and were conducted in English. The interview schedule focused on participants' working experiences as well as their engagement with and opinions on the Estonian game industry. I chose to anonymise the interview data to protect interviewees and third parties. Therefore, this article employs pseudonyms and intentionally vague descriptions of interviewees' occupational roles. Thematic analysis was also utilised to construct main themes from primary and secondary data. The question of connections between local, national, regional, and international game production was one of the primary themes that emerged from the analysis, indicating

The interviewees came from different countries and backgrounds, including Estonia, Russia, Canada, Sweden, Italy, and Pakistan. The use of English was justified as this is a lingua franca for individuals working in the game industry. However, the use of English with non-native English speakers also has its limitations as it can increase the risk of miscommunication. tensions faced by small, national game developers attempting to produce games for the international gaming market.

\section{DIGITAL GAMES PRODUCTION IN ESTONIA}

There is not much information about the history of the Estonian digital games culture and industry before 1990s. However, it can be speculated that as a part of the Soviet Union before 1991, Estonia was under the CoCom (Coordinating Committee for Multilateral Export Controls) embargo and had limited access to knowledge exchange and technology transfer from western alliance countries, similarly to the case of Poland and Czechoslovakia (see Švelch 2018). The earliest records indicated the game SkyRoads from 1993, developed by Bluemoon studio, as the first internationally successful Estonian production. According to interviewees, the development and expansion of companies related to game production in the country started much later in the mid-2000s with the emergence of major mobile games studios such as Creative Mobile and entrepreneurial initiatives dedicated to supporting small game development teams (e.g. GameFounders accelerator) (GameFounders 2021).

Creative Mobile, established in 2010, is currently considered the main digital game development company in Estonia due to its position in supporting other companies, publishing games but also organising and supporting local events such as Game Dev Days or IGDA Estonia meetings. Around the mid-2000s, other companies also specialised in mobile games, especially "casual" or "hyper-casual" games emerged. The increased interest in development of mobile games during this time is not limited to Estonia, as the "boom" in mobile game development was increasingly visible worldwide since 2012, with a lowering barrier of entry to the game development market facilitated by the popularisation of accessible development tools, publishing platforms and an expanding player base (Juul 2009). 
The establishment of mobiles games in Estonia is not the only thing that inspired the local game making community organisers. Interviewees argued that the Finnish game industry was used as a model for organising the Estonian game development community. The inspiration points usually referred to organising the industry in the form of local communities, establishing the national chapter of the IGDA (similar to its equivalent in Finland), focusing on organising game jams and peer support and connections with start-up culture. There is also evidence of cooperation between the two national industries. The development of the local community was possible through a range of initiatives that supported the organisation of meetups for game makers in Tallinn (IGDA Estonia, Game Lab) and Tartu (APT Game Generator) as well as entrepreneurial initiatives to establish new digital games and related companies (e.g., GameFounders Accelerator in 2012). However, while there is a possibility of identifying similarities in the development of the game industries in Finland and Estonia, these two countries share significant differences. For example, Jørgensen et al. (2015) demonstrated that the Finnish industry developed from a significant demo scene, connections to well established ICT companies (such as Nokia) and the country's state welfare policy.

While Estonian the game makers community often draws inspirations from Finland, its structure and development is closer to the structure and socio-historical development of game communities in Latvia and Lithuania. According to reports about the game development communities in the Baltic countries, the industries in these countries are organised around local game making communities, dominated by mobile game companies, online gambling companies and small, independent contractors or development teams (see BGI 2021). The communities supporting game makers were established in these countries around 2015 and are further driven by short-term initiatives, often directed towards supporting the entrepreneurial potential of digital games or related companies. Interviewees also argued that game development does not have the same cultural legitimacy as it does in Finland. They identified the limited awareness of the sector among government officials and society at large, as well as the lack of 'financially and internationally successful' game productions that would provide wider attention and credibility to the national sector. Interviewees also drew attention to the fact that the games industry is rarely part of discussion about technological advancement in Estonia and discourse about digital society. Andrew, (game journalist) argued: "It's weird what's happening in Estonia right now, because we have this e-society and so on, but we don't support the gaming industry, because people just don't understand it".

Interviewees also argued that the Estonian game industry is highly fragmented and consists of various companies directly and indirectly supporting digital game development. The local chapter of the IGDA provides information about the number and types of companies associated with the game industry in the country. As of 2020, the Estonian game industry consists of 83 companies. However, further analysis indicates that not all these companies are directly engaged in game development. Only 33 companies are engaged with game development with the rest of the listed companies including service providers/outsources (36), online casinos (4), community organisations (3) or unidentified companies (7). ${ }^{2}$ The problem of assessing the size of the industry in Estonia was also repeatedly mentioned by interviewees who indicated that the IGDA list often does not include newly established companies or that the competitive nature of the digital games market means that some of the companies listed by the IGDA are no-longer actively engaged in game development. Some of interviewees openly questioned whether

2 By 'unidentified', I mean companies which could not be find through their websites, registered as companies in Estonia or through social media. Therefore, there is also no information as to whether these entities are still operating or working within the game industry. 
companies directly and indirectly engaged in game development in Estonia could be classified as 'the game industry,' as one of the survey respondents argued "It's bad. We really don't have an industry since all of the companies make Facebook games or mobile games". This comment also demonstrates the cultural and social value attributed to mobile and casual game development as "not-real" industry in the national context. This comment also relates to the lack of Triple- $\mathrm{A}^{3}$ game development studios in the country or substantial engagement in small scale game development for commercial and non-commercial purposes.

The data from the interviews, the survey and observations demonstrate that the Estonian community could be divided into three broad categories of engagement in game development. The first category refers to established companies, interested in commercial game development. These companies often engaged in mobile games development or providing support services to international clients (e.g. arts assets development). Local studios often combine developing their own games alongside taking on outsourced work in order to obtain sustainability in the competitive international digital games market. The second category consists of online gambling companies which, while not directly engaging in game development, play an important role in supporting the local industry (e.g., organisation of events, sponsorship) or providing employment opportunities. ${ }^{4}$

The last category consists of game makers communities which aim to develop games for non-commercial purposes and are also investing in more artistic or innovative approaches to game making. This more independent, artistic, and experimental approach to game making is developed

Triple A - an informal classification that designates games published by mid-size and major publishers, which usually have higher development and marketing budgets.

$4 \quad$ Playtech is the biggest employer in the sector of 'entertainment software' in Estonia. Students of game related courses are also often engaged in internships and job opportunities with online gambling companies based in the country. through the game making community in Tartu. In opposition to the events organised by the IGDA Estonia, which were dedicated to the business of game development and mobile games market because of the leading role of Creative Mobile in supporting these events. Consequently, what is recognised as "the digital games industry" does not have clear boundaries, and rarely refers to the various local, national, and regional conditions, but only to game development studios. Considering the various studies about the socio-historical development of the local and national industries, the dominant form of work in the industry consists of subcontracted work, service support companies and small developers which also contribute their skills to other media industries. Furthermore, many members of the community preferred to refer to themselves as "hobbyists" rather than "independent" developers indicating that their engagement with game making is mostly for non-commercial purposes. This example also refers to the blurring of the boundaries between informal and formal game making as it attracted wider groups of participants interested in game development (see Keogh 2019). This recognition requires further attentiveness to questions about what constitutes a "digital games industry" in the first place, as assessed in the case of other media industries (see Caldwell 2013).

\section{DISCO ELYSIUM AND GAME MAKING COMMUNITIES IN ESTONIA}

Game making communities in Estonia saw the international recognition and financial success of Disco Elysium as beneficial as it has drawn attention to game development in the country. Interviewees argued that the game may increase the visibility of game development in Estonia in the global gaming industry, and potentially lead to further support and endorsement from the Estonian government. In understanding the spatial politics of game making, it is important to consider the impacts of regional and national policies on local production. As Kerr (2017) argues, there 
has been increased activity by national institutions and organisations in developing policies or supporting programs for the game industry in the last decade. The scope and influence of such policies vary greatly in terms of offered support programs and purposes (such as attracting foreign investments or boosting entrepreneurship in the country) (see Kerr, 2017). This further demonstrates the importance of paying attention to the national and regional regulations that are shaping the spatial politics of game production. While paying attention to only a national scope of analysis of game production might be misleading, especially without acknowledging the extensive international production networks in the industry and operations of transnational media companies within the sector, nationally implemented policies have a significant impact on the development of game making communities in each country.

In Estonia, support for national and regional (European Union-funded) game development has been provided through targeted tech sector funding schemes (such as Enterprise Estonia) or dedicated to the industry via short-term grants or incubation schemes, such as the Baltic Games Industry (on going) GameFounders project (closed in 2012). This was characterised by short-term cycles and offering various forms of support, from funding local events (partially covering IGDA Estonia operations, allowing local developers to attend game industry events in other countries) to providing mentoring in different facets of game development (BGI 2021).

However, interviewees argued that more substantial and long-term funding for game development-related initiatives would be beneficial for local communities. This view was consistent with the survey data results, which showed that $57 \%$ of respondents indicated that the Estonian government provides insufficient support for the local game industry. According to the survey data, respondents were mostly in favour of further support, such as direct funding for game development (28\%), followed by support in terms of investments in game development-related education and tax reliefs. The least favourable form of support was government engagement in the promotion of Estonian game developers outside of the country. The choice of this type of support as the least favourable might be related to the fact that support in promoting game developers from Estonia is already offered, such as supporting the attendances of developers at conferences. One of the representatives of the IGDA Estonia argued that because of the high risk of game production, national game developers often have problems finding private investors in the country as well as trying to finance game development through their own financial resources. Therefore, the lack of long-term support for game developers and the current stage of development of the game industry in Estonia both contribute to the precarious position of local commercial game makers.

For small-scale and developing game maker communities in Estonia, the international success of Disco Elysium was seen as evidence that financially viable, successful, and socially recognised game productions can be developed in the country. Interviewees hoped that the news of Disco Elysium's commercial and critical success would attract further attention from the government and potentially contribute to investments in future support for the national industry. In addition to more long-term investments in the industry, they mentioned that government attention could result in providing more publicity and recognition to the sector as well as investments in game-related education (skills development). However, the wide recognition of games developed in Estonia has been partly dictated by the fact that Disco Elysium is not the only game local studios have developed successfully. For example, a local community opened a Steam webpage with games developed or related to development in Estonia to support game makers from the country (Steam Curator 2021). While the example of Disco Elysium and other successful recently published games by Estonian developers could be used to 
lobby the national government to make further investments in the game industry (broadly defined), interviewees argued that successfully publishing games related to Estonia also brings more attention to the national sector. As previously discussed by scholars who investigated game development in Canada (Joseph 2012; Parker, Jenson, 2015), reference to a "national" level of identification was used mostly in relation to game development to leverage/lobby for further national resources/government support (broadly defined). However, national identification might also stem from the need to assert the Estonian community and game production on the international game market, while in the case of countries in Western Europe and North America, this tendency is less prominent because of access to infrastructure and resources, and the longer history of game industry development. Therefore, the spatial politics of game production at the national level refer to the operations of national and regional institutions and organisations in terms of supporting the sector in relation to the international games industry.

\section{DISCO ELYSIUM AND INTERNATIONAL PRODUCTION NETWORKS}

In this section, I would like to focus on the spatial politics of game production processes by taking a closer look at Disco Elysium's development process and its engagement in various international production networks. In 2017, a part of the development team decided to relocate their game production to London. According to interviews with team members, the relocation was motivated by a couple of reasons, including easier access to "core" production decisions, a new talent pool, and the UK tax relief for game development (Batchelor 2017). The relocation decision was not surprising but was, rather, exemplary of game production's spatial politics. As in other examples of digital labour, work in digital games is characterised "by both "placelessness' and stickiness, by both dispersion and spatial concentration" (Flecker 2016: 2, emphasis in original) and is dictated by sociohistorical developments of given game industries, national and regional policies and dynamics of international game production trends.

The example of Disco Elysium can be used to understand how the sociohistorical development of a given national or regional game industry in relation to global games production impacts the construction of game development/making spaces. ZA/UM studio's decision was motivated by the acknowledgment of the challenges involved in developing and marketing a game within Estonia both in terms of material (existing infrastructure, access to a talent pool) and sociocultural (symbolic associations of Estonia with the support service aspect of game development) factors. One of the interviewees, Andrew (a game journalist), pointed out:
Why the hell should anyone come here to develop a video game? One of my best friends is working for Disco Elysium, and half of their office has been moved to London. Their main reason for doing that was because no one would pick up a phone call from Estonia. Like, gaming journalists or publishers. [...] Because the overall feeling is like, "Estonia-what's that?"

The same perspective was shared by Disco Elysium executive producer, Kaur Kender, who argued that establishing a presence in major game production regions (e.g. Western Europe or North America) is crucial for the successful development and marketing of a game:

You can't really market something out of Estonia. The internet is one big lie-if it were true, we'd all be sitting around watching Chilean and Peruvian movies not making video games. If you want to market something, you have to be in London or maybe Los Angeles. There are no other options and no other places in Europe to do 
marketing like this (Kaur Kender in Batchelor 2017).

The above presented perspectives indicate the importance of the construction of game production spaces in terms of access to resources and infrastructure in defining successful game production. While companies that have been directly and indirectly engaged in digital game production in Estonia have contributed to the overall development of international game production (through mostly providing subcontracted work and support), game development in the country is associated with small-scale development, mobile game development or outsourcing. This narrative has directed our attention to the economic and sociocultural construction of game-making spaces as "core" and "peripheral" in Europe, with Eastern European and Baltic countries often being approached as spaces of support and relatively cheaper labour costs. This situation further emphasises the asymmetry of power among different digital game companies from different geographical regions and value chains (see Johns 2006).

Furthermore, the production of Disco Elysium is emblematic of international production networks observed in digital game industries not only because of the ZA/UM decision to move part of its development team to the UK but also as a result of engagement with companies from different parts of the world and from different parts of the game production value chain, including Estonia, Romania, Poland and China (IGDB 2021). The development of Disco Elysium was supported by ZA/UM team members and contractors based in Estonia. The release of the game was widely acknowledged by the local game-making community in Estonia. Undoubtedly, it was the first internationally and universally acclaimed game of this size within the country or the wider Baltic region. In other words, as one of the interviewees in this study, Michael, an independent game developer, noted, "A lot of people [from the game making community in Estonia] are saying "our game" because we're the people who worked on it
[...] I mean, this is nice. We should be proud of this, right?" However, work on Disco Elysium was also subcontracted to a Polandbased studio, Kings of Unity (2021), which specialises in "polishing UI design, localisation, bug fixing, dialogue system expansion' and external QA (quality assurance/testing) and a team from Romania (part of testing and localisation studios owned by Testronic Group). Furthermore, the game's marketing was supported by a public relations company from the UK, and localisation was provided by Whisper Games from Xiamen, China. The contributions of the companies listed above to the development and support of Disco Elysium provide further insights into the spatial politics of game production, with game developers relying on networks of various contractors (parts of international companies like Testronic, smaller national development teams like Kings of Unity or individual contractors as in the case of some of the interviewees from Estonia who supported the development of the game). These examples demonstrate that the spatial politics of game production need to be acknowledged through an investigation of different spatial levels of production by acknowledging the positioning of Estonian game development in relation to the global game industry and cost incentives (e.g., lower labour costs, available talent pools) in international production networks and national state policies.

\section{CONCLUSION}

This article examines the development of Disco Elysium by positioning it within the context of game making communities in Estonia and their relations with national, regional and international production networks. The article outlined the socio-historical development of the games industry in Estonia and its current structure. Furthermore, using Disco Elysium as an example, the article demonstrated the importance of investigating game development by attending to the connectedness of different spatial levels of influence in game production.

This demonstrates that paying attention to the spatial politics of game produc- 
tion can reveal how the spatial reach and embeddedness of game companies and related institutions are contingent upon several regional, national, and international factors (see Kerr 2017). By doing so, the article discusses aspects of spatial politics in game production that are visible at the level of regional development, national regulations, and international production networks. The development and current structure of the Estonian game industry are still influenced by cooperation with, and inspiration from, neighbouring countries - notably Finland and other Baltic countries (especially Latvia and Lithuania). The small-scale and fragmented nature of the game industry in Estonia contributes to its classification as "peripheral" compared to the industries of major game-producing nations in Western Europe, North America, or East Asia. From a domestic perspective, the international recognition of Disco Elysium has had significant implications for game-making communities in Estonia. It has brought to the public's attention the existence of game development in the country and has aided attempts to lobby for further governmental support of the domestic game industry. However, the power asymmetries of the global game industry in terms of access to infrastructure, private and public support, and skills development, all influenced the decision to move part of the Disco Elysium development team to the United Kingdom. Furthermore, the use of large networks of contractors to support the development and delivery of the game is emblematic of international production networks in the global game industry.

\section{REFERENCES}

Batchelor, James 2017. 'Making games under threat of nuclear war. Why Estonian developer ZA/UM is moving its team to the safety of a new London studio'. Gamesindustrybiz https://www.gamesindustry.biz/ articles/2017-07-20-making-games-under-threat-ofnuclear-war (21 July 2021).

BGI 2021. Baltic Game Industry. https://baltic-games. eu/171/ (21 July 2021).

Bluemoon 1993. SkyRoads. Tallinn: Bluemoon. http:// www.bluemoon.ee/history/skyroads/ (19 August 2021). Caldwell, John T. 2013. 'Para-Industry: researching Hollywood blackwaters'. - Cinema Journal 52,3, 157-165. Christopherson, Susan 2006. 'Behind the screens. How transnational firms are constructing new international division of labor in media work'. - Geoforum 37, 739-752. Eesti Instituut 2020. Digital Culture News: Estonian video game Disco Elysium is taking the gaming world by storm. https://estinst.ee/en/digital-culture-newsestonian-video-game-disco-elysium-is-taking-thegaming-world-by-storm/ (21 July 2021).

Estonian Institute of Economic Research [EKI] 2018. 12_Meelelahutustarkvara. https://www.ki.ee/publikatsioonid/valmis/12._Eesti_loomemajanduse_olukorra_uuring_ja_kaardistus_-_Meelelahutustarkvara. pdf (8 August 2021).

Flecker, Jörg 2016. Introduction - Jörg, Flecker (ed.), Space, Place and Global Digital Work, 1-8. London: Palgrave Macmillan.

GameFounders 2021. Game Founders Accelerator. http://www.gamefounders.com (8 August 2021). IGDB 2021. Disco Elysium (credits). https://www.igdb. com/games/disco-elysium/credits (21 July 2021). Izushi, Hiro; Aoyama, Yuko 2006. 'Industry Evolution and Cross-Sectoral Skill Transfers: A Comparative Analysis of the Video Game Industry in Japan, the United States, and the United Kingdom: - Environment and Planning A: Economy and Space 38, 10, 1843-1861. Johns, Jennifer 2006. 'Video games production networks: value capture, power relations and embeddedness'. - Journal of Economic Geography 6, 2, 151-180. Jørgensen, Kristine; Sandqvist, Ulf; Sotamaa, Olli 2017. 'From hobbyists to entrepreneurs: on the formation of the Nordic game industry.' - Convergence 23, 5, 457-476.

Joseph, Daniel 2012. 'The Toronto indies: some assemblages required'. - Loading... The Journal of the Canadian Game Studies Association, 7, 11, 92-105. Juul, Jesper 2009. A Casual Revolution: Reinventing Video Games and their Players. Cambridge: MIT Press. Keogh, Brendan 2019. 'The cultural field of video game production in Australia'. - Games and Culture 16, 1, 116-135.

Kerr, Aphra 2006. The Business and Culture of Digital Games: Gamework and Gameplay. London: Sage Publications.

Kerr, Aphra 2014. 'Placing international media production'. - Media Industries Journal 1, 1, 27-32. Kerr, Aphra 2017. Global Games: production, circulation and policy in the networked era. New York: Routledge. Kerr, Aphra; Cawley, Anthony 2012. 'The spatialisation of the digital games industry: lessons from Ireland' - International Journal of Cultural Policy 18, 4, 398-418. Kings of Unity 2021. Kings of Unity Main Page. https://www.theknightsofunity.com (21 July 2021). Lefebvre, Henri [1974] 1991. The Production of Space. Translated by Donald Nicholson - Smith. Oxford: Blackwell.

Liboriussen, Bjarke; Martin, Paul 2016. 'Regional game studies'. - Game Studies, 16, 1. http://gamestudies. org/1601/articles/liboriussen (8 August 2021). Mosco, Vincent 1996. The Political Economy of Communication. London: Sage.

Nieborg, David B.; de Kloet, Jeroen 2016. 'A patchwork of potential: a survey of the European game industry'. - 
Anthony Fung (ed.), International game industries and cultural policy, 201-226. London: Palgrave Macmillan. Ozimek, Anna M. 2018. Videogame Work in Poland Investigating Creative Labour in a Post-socialist Cultural Industry. PhD Thesis. University of Leeds.

Parker, Felan; Jenson, Jennifer 2017. 'Canadian indie games between the international and the local'. -

Loading... Canadian Journal of Communication 42, 5 , 867-891.

Sotamaa, Olli 2021. 'Studying game development cultures'. -Games and Culture [Online First] 1-20. Steam Curator 2021. Estonian Games. https://store. steampowered.com/curator/36235895-EstonianGames/ (8 August 2021).

Švelch, Jaroslav 2018. Gaming the Iron Curtain: How Teenagers and Amateurs in Communist Czechoslovakia Claimed the Medium of Computer Games. Cambridge: MIT Press. 